\title{
Impact of Coronary Collateral Circulation of Perioperative Myocardial Damage in High-Risk Patients Undergoing Coronary Artery Bypass Grafting Surgery
}

\author{
Haci Ali Ucak, MD, Hasan Uncu, MD \\ Department of Cardiovascular Surgery, University of Health Sciences Adana City Training and Research Hospital, Adana, Turkey
}

\section{ABSTRACT}

Background: Coronary collateral circulation (CCC) is a small vascular formation that allows the connection between the different parts of an epicardial vessel or other vessels. The presence of collateral circulation contributes positively to the course of coronary artery disease (CAD). The aim of this study was to investigate the effect of collateral circulation on myocardial injury and clinical outcomes during coronary artery bypass grafting (CABG) in a high-risk patient group.

Methods: 386 patients who underwent isolated CABG under cardiopulmonary bypass (CPB) were included in the study. Patients were divided into two groups according to the Rentrop scores ( $n=225$ poor CCC group; and $n=161$ good CCC group). Myocardial injury and postoperative clinical results were evaluated as endpoints.

Results: The mean age was $62.9 \pm 7.5$ years, and $61.6 \%$ of all patients were male. Postoperative 30-day mortality rate was significantly higher in poor CCC group (4 [1.7\%] and $1[0.6 \%], P<.001)$. The frequency of postoperative intraaortic balloon pump (IABP) use (5 [2.2\%] and 1 [0.6\%], $P<.001)$, low cardiac output syndrome (LCOS) $(28$ [12.4\%] and $10[6.2 \%], P<.001)$ and postoperative atrial fibrillation $(35[15.6 \%]$ and $16[9.9 \%], P=.038)$ were significantly higher in poor CCC group. 12th and 24th hour CK-MB and cTn-I values were found to be significantly lower in the good CCC group.

Conclusion: It is inevitable that the $\mathrm{CPB}$ circuit and operation have devastating effects on myocardium in CABG operations. The presence of CCC reduces postoperative myocardial injury, low cardiac output syndrome, and mortality rates.

\section{INTRODUCTION}

Any cardiac surgery performed under cardiopulmonary bypass (CPB), including coronary artery bypass grafting surgery $(\mathrm{CABG})$, is associated with cardiac cell damage to a certain extent, regardless of how it is performed. Myocardial damage caused by the created and controlled ischemiareperfusion periods during operation is one of the important

Received March 27, 2019; accepted fuly 25, 2019.

Correspondence: Haci Ali Ucak, University of Health Sciences Adana City Training and Research Hospital, Kisla Road, 01370 Yuregir, Adana, Turkey; +90-322-455-9000; +90-530-690-6034 (e-mail: dr.haliucak@gmail.com). causes of postoperative morbidity and mortality. Especially in CABG, the severity of coronary disease, incomplete revascularization, recent myocardial infarction, and early graft occlusions are the possible causes of myocardial injury. Systemic and topical hypothermia is used to minimize the energy consumption of tissues and therefore to minimize myocardial damage when under CPB. In addition, before the coronary anastomosis and immediately after the placement of the cross-clamp, antegrade and/or retrograde given cardioplegia provides myocardial diastolic arrest and transfers the components which the tissue needs through the coronary circulation to the cells. Thus, minimizing the oxygen consumption and consequently keeping the cardiac necrosis at the minimum level are the aims. Although minimizing this damage caused by the innovative methods is the goal, the distribution of the cardioplegia solutions may not be possible towards the heart tissue due to the nature of coronary artery disease (CAD). In this case, cardioplegia solutions cannot efficiently achieve the desired effect on the myocardium. Cardiac troponin I (cTnI) and creatine kinase-myocardial band fraction (CK-MB) are frequently preferred laboratory tests to detect damage in the myocardial tissue [Aldous 2013; Adabag 2007].

Coronary collateral circulation (CCC) is an important adaptive mechanism for the protection from the ischemic myocardium. Morbidity and mortality are known to be lower in CAD patients with a well-developed CCC [Meier 2007]. We believe that this collateral system may have a significant effect on the preservation of vitality and function of myocardial tissue during coronary artery surgery.

The aim of this study is to evaluate the relationship between preoperatively evaluated CCC, and postoperative myocardial injury and clinical outcomes in high-risk patients who underwent CABG operation.

\section{MATERIALS AND METHODS}

The data of 1318 patients who underwent isolated CABG operation under CPB due to CAD between 2014-2018 were analyzed. Among these patients, preoperative, intraoperative, and postoperative data of 435 patients who were found to be at high risk by the reference to the European System for Cardiac Operational Risk Assessment (EuroSCORE) II scoring system and whose coronary angiography images could be reached were analyzed. Patients who had acute myocardial infarction (AMI) for 10 days before the operation, who had elevated CK-MB and/or cTnI levels while taken into the 


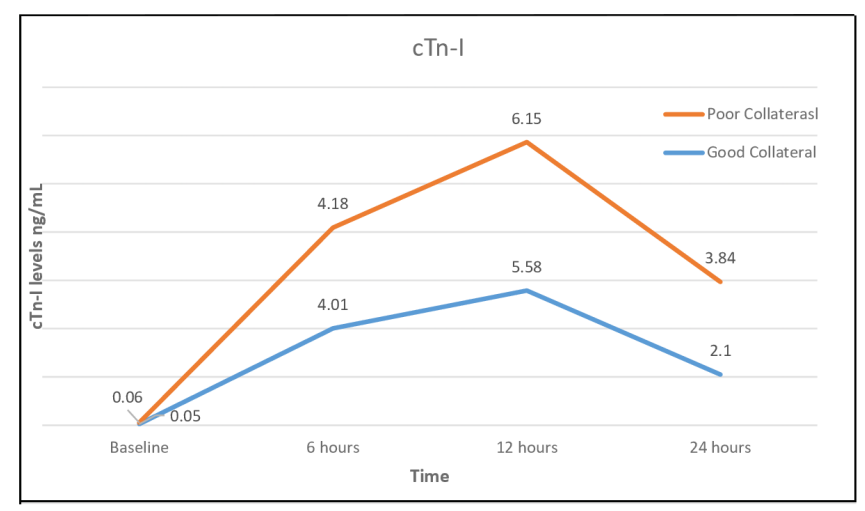

Figure 1. A linear graph for both groups showing cardiac troponin-I levels in blood samples taken before surgery, before the operation, at the 6th hour, at the 12th hour, and at the 24th hour.

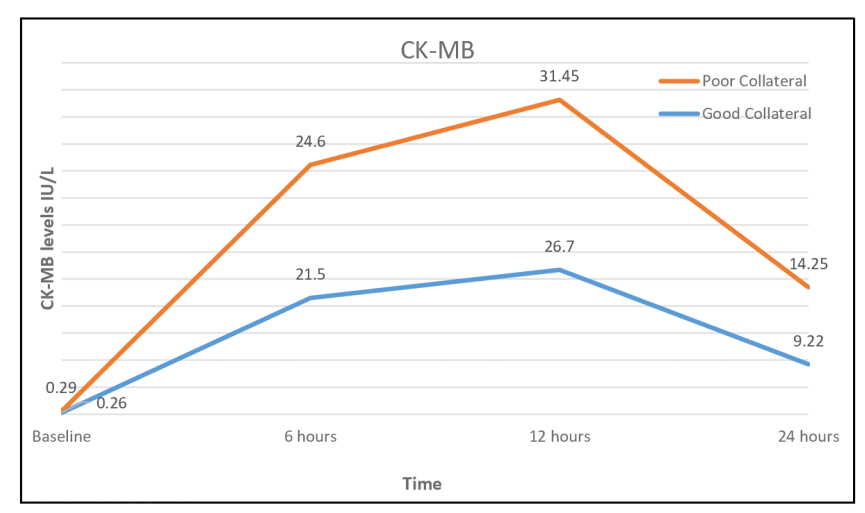

Figure 2. A linear graph for both groups showing CK-MB levels in blood samples taken before surgery, before the operation, at the 6th hour, at the 12th hour, and at the 24th hour.

operation, or who underwent urgent operation were excluded from the study. In conclusion, a total of 386 patients were included in this retrospective study.

All patients underwent coronary angiography within 6 months prior to operation, had transthoracic echocardiographic examinations, and their blood samples were taken. The laboratory results of the blood samples taken before and after the operation, the duration of $\mathrm{CPB}$ and cross-clamping, intraoperative data, hemodynamic measurements obtained in the intensive care and service follow-up and clinical data were obtained from the database of our institute. Angiography images of the patients were evaluated by 2 cardiac surgeons and an interventional cardiologist. The Rentrop classification was used for CCC, while SYNTAX scoring system was used for the severity and complexity of CAD [Rentrop 1988; Sianos 2005]. According to the Rentrop scoring system; grade 0: no collateral filling is observed; grade 1: monitoring the lateral branches of the artery filled by collateral arteries without monitoring the epicardial segment; grade 2: partially
Table 1. Baseline Characteristics of Patients

\begin{tabular}{|c|c|c|c|}
\hline & $\begin{array}{c}\text { Poor CCC } \\
\text { Group } \\
\text { (Rentrop 0-1) } \\
\mathrm{n}=225\end{array}$ & $\begin{array}{c}\text { Good CCC } \\
\text { Group } \\
\text { (Rentrop 2-3) } \\
n=161\end{array}$ & $P$ \\
\hline Male, n (\%) & $143(63.5)$ & $95(59)$ & .821 \\
\hline Age, y & $62.7 \pm 7.8$ & $63.1 \pm 8.2$ & .752 \\
\hline $\mathrm{BMI}, \mathrm{kg} / \mathrm{m}^{2}$ & $30.1 \pm 5.1$ & $29.8 \pm 4.2$ & .927 \\
\hline LVEF, \% & $57.4 \pm 9.9$ & $51.8 \pm 10.2$ & $<.001$ \\
\hline $\begin{array}{l}\text { Recent myocardial } \\
\text { infarction within } 90 \mathrm{~d}, \mathrm{n}(\%)\end{array}$ & $105(46.7)$ & $74(42.2)$ & .051 \\
\hline Euroscore II, \% & $6.1 \pm 4.9$ & $6.6 \pm 4.2$ & .194 \\
\hline Diabetes, n (\%) & $85(37.8)$ & $65(40.6)$ & .203 \\
\hline Hypertension, n (\%) & $114(50.6)$ & $92(57.1)$ & .035 \\
\hline COPD, n (\%) & $48(21.3)$ & $35(21.7)$ & .578 \\
\hline Dyslipidemia, n (\%) & $38(16.9)$ & $32(19.9)$ & .165 \\
\hline Chronic kidney failure, n (\%) & $5(2.2)$ & $2(1.5)$ & .672 \\
\hline Peripheral arterial disease, $\mathrm{n}(\%)$ & $52(23.1)$ & $53(32.9)$ & $<.001$ \\
\hline Preoperative stroke or TIA, n (\%) & $6(2.6)$ & $5(3.1)$ & .719 \\
\hline Smoking, $\mathrm{n}(\%)$ & $110(48.9)$ & $82(50.9)$ & .349 \\
\hline Syntax score & $25.3 \pm 10.2$ & $30.7 \pm 9.5$ & .036 \\
\hline LMCA lesion, $\mathrm{n}(\%)$ & $35(15.5)$ & $42(26.1)$ & $<.001$ \\
\hline \multicolumn{4}{|l|}{ Occluded artery, n (\%) } \\
\hline LAD Artery & $108(48)$ & $98(60.9)$ & .057 \\
\hline Cx Artery & $63(28$ & $42(26.1)$ & .412 \\
\hline RCA & $94(41.8)$ & $85(52.7)$ & .354 \\
\hline
\end{tabular}

BMI indicates body mass index; LVEF, left ventricle ejection fraction; COPD, chronic obstructive pulmonary disease; TIA, transient ischemic attack; LMCA, left main coronary artery; LAD, left anterior descending; Cx, circumflex; RCA, right coronary artery.

Bold values indicate statistical significance.

filling the epicardial artery by collateral circulation; grade 3: complete filling of the epicardial vein by the collateral arteries. If more than one collateral system was detected in the patient, the higher value of CCC score was accepted. Patients were divided into two groups as poor (grade 0-1) and good (grade 2-3) according to the Rentrop scores. The same team that performed angiographic examination has also identified the prevalence of CAD using the online calculator at www.syntaxscore.com.

All operations were performed under general anaesthesia, $\mathrm{CPB}$, and via median sternotomy in accordance with our routine clinical practice. Following premedication, anesthesia was started by giving fentanyl, midazolam, and sodium thiopental to the patient respectively, and volatile anesthetic agents (sevoflurane or desflurane) were used to maintain anesthesia. After systemic heparinization $(300 \mathrm{U} / \mathrm{kg})$, the 
Table 2. Intraoperative and Postoperative Data

\begin{tabular}{|c|c|c|c|}
\hline & $\begin{array}{c}\text { Poor CCC } \\
\text { Group } \\
\text { (Rentrop 0-1) } \\
n=225\end{array}$ & $\begin{array}{c}\text { Good CCC } \\
\text { Group } \\
\text { (Rentrop 2-3) } \\
n=161\end{array}$ & $P$ \\
\hline X-clamp time, $\mathrm{m}$ & $49.7 \pm 14.1$ & $47.4 \pm 11.9$ & .841 \\
\hline CPB time, $\mathrm{m}$ & $92.1 \pm 18.6$ & $94.2 \pm 16.3$ & .672 \\
\hline Ventilator time, $\mathrm{h}$ & $17.5 \pm 9.7$ & $17.1 \pm 8.9$ & .715 \\
\hline Number of distal anastomosis & $2.8 \pm 1.4$ & $3.3 \pm 1.6$ & .197 \\
\hline Incomplete revascularization, n (\%) & $14(6.2)$ & $5(3.1)$ & .025 \\
\hline Postoperative MI, n (\%) & $3(1.3)$ & $2(1.25)$ & .841 \\
\hline Use of IABP, n (\%) & $5(2.2)$ & $1(0.6)$ & $<.001$ \\
\hline LCOS, n (\%) & $28(12.4)$ & $10(6.2)$ & $<.001$ \\
\hline $\begin{array}{l}\text { Postoperative myocardial infarc- } \\
\text { tion, } \mathrm{n}(\%)\end{array}$ & $3(1.3)$ & $1(0.6)$ & .057 \\
\hline $\begin{array}{l}\text { Postoperative atrial fibrillation, } \\
\mathrm{n}(\%)\end{array}$ & $35(15.6)$ & $16(9.9)$ & .038 \\
\hline Acute renal failure, $\mathrm{n}(\%)$ & $3(1.3)$ & $2(1.2)$ & .794 \\
\hline TIA/Stroke, n (\%) & $4(1.7)$ & $3(1.8)$ & .695 \\
\hline Respiratory failure, n (\%) & $9(4)$ & $5(3.1)$ & .714 \\
\hline Mechanical ventilation time, $\mathrm{h}$ & $6.8 \pm 4.1$ & $6.4 \pm 3.7$ & .812 \\
\hline ICU stay, d & $2.4 \pm 1.9$ & $2.4 \pm 1.7$ & .798 \\
\hline Mortality in 30 days, $\mathrm{n}(\%)$ & $4(1.7)$ & $1(0.6)$ & $<.001$ \\
\hline
\end{tabular}

CPB indicates cardiopulmonary bypass; MI, myocardial infarction; IABP, intraaortic balloon pump; LCOS, low cardiac output syndrome; TIA, transient ischemic attack; ICU, intensive care unit.

Bold values indicate statistical significance.

activated clotting time (ACT) was increased to over 480 seconds, and an additional dose of heparin was applied to maintain this value. CPB was applied following arterial and venous cannulation. The patient was cooled to $32-34^{\circ} \mathrm{C}$ and entered into moderate hypothermia. Following the aortic cross-clamping, a diastolic arrest was achieved by administering $12-14 \mathrm{~mL} / \mathrm{kg}$ of warm blood cardioplegia. Additional cardioplegia doses were given from the aortic root and completed coronary anastomoses for every 15-20 minutes during the operation. CPB was stopped and protamine sulphate was initiated to antagonize heparin activity. All patients were admitted to the intensive care unit, and they were extubated after the full clinical stability and adequate wakefulness was achieved. Blood samples were taken for CK-MB and cTnI values at postoperative 6 th, 12th, and 24th hours. All patients underwent a transthoracic echocardiographic examination to check postoperative myocardial function. The patients who were divided into two groups according to the Rentrop scores were evaluated for myocardial injury with reference to CK-MB and cTnI values. Postoperative clinical results were also evaluated as secondary endpoints.
Table 3. Multivariate Analysis for Independent Risk Factors of LCOS

\begin{tabular}{lccc}
\hline & $95 \% \mathrm{Cl}$ & Odds Ratio & $P$ \\
\hline Older age (>65 years old) & $1.34-3.57$ & 2.14 & $<.001$ \\
Incomplete revascularization & $1.53-4.15$ & 2.57 & .024 \\
LMCA lesion & $1.65-5.42$ & 3.45 & .045
\end{tabular}

\section{Statistical Analysis}

SPSS 25.0 for Windows (SPSS, Chicago, IL, USA) was utilized for the statistical analysis. All data were evaluated with regards to the normal distribution using the KolmogorovSmirnov test. Continuous variables were compared with Student $t$ test or Mann-Whitney $U$ test according to the distribution of the data. Categorical variables were compared using the chi-square test. Categorical variables were identified as percentages and continuous variables as mean \pm standard deviations. Univariate logistic regression analysis was performed to evaluate the relationship between baseline values and LCOS. Odds ratios (OR) are given with the $95 \%$ confidence intervals (CI). Baseline variables which were found to be significantly associated with LCOS $(P<.05)$ in univariate regression analysis were determined. Multiple logistic regression analysis was used to assess the independent predictors of LCOS.

\section{RESULTS}

A total of 386 patients who underwent CABG under $\mathrm{CPB}$ and under elective conditions in our department were included in the study. The mean age was $62.9 \pm 7.5$ years, and $61.6 \%$ of all patients were male. After calculating the Rentrop scores, 225 patients were in poor CCC group and 161 patients were in good CCC group. Syntax score values were significantly higher in good CCC group $(25.3 \pm 10.2$ and $30.7 \pm 9.5, P=.036)$. The prevalence of hypertension (114 [50.6\%] and $92[57.1 \%], P=.035)$, peripheral arterial disease $(52[23.1 \%]$ and $53[32.9 \%], P<.001)$ and left main coronary artery (LMCA) lesions (35 [15.5\%] and 42 [26.1\%], $P<.001)$ were higher in the CCC group. The left ventricular ejection fraction (LVEF) was significantly lower in good CCC group $(57.4 \pm 9.9$ and $51.8 \pm 10.2, P<.001)$. On the other hand, no significant differences were observed between groups in terms of age, sex, body mass index (BMI), diabetes, dyslipidaemia, chronic obstructive pulmonary disease (COPD), chronic kidney failure, smoking, and Euroscore 2 values (Table 1).

When the intraoperative data were compared between the groups, cross-clamping and $\mathrm{CPB}$ durations were found to be similar (Table 2). Although the number of distal anastomoses was lower in group 1 , the difference was not statistically significant $(2.8 \pm 1.4$ and $3.3 \pm 1.6, P=.197)$. The incomplete revascularization rates were significantly higher in poor CCC group (14 [6.2\%] and $5[3.1 \%], P=.025)$. The frequency of postoperative intraaortic balloon pump (IABP) use (5 [2.2\%] 
Table 4. Myocardial Enzyme Levels

\begin{tabular}{|c|c|c|c|c|c|c|}
\hline Preoperative & $0.29 \pm 0.051$ & $0.26 \pm 0.29$ & .541 & $0.06 \pm 0,04$ & $0.05 \pm 0.03$ & .284 \\
\hline 6 hours & $24.6 \pm 5.9$ & $21.5 \pm 6.8$ & .068 & $4.18 \pm 1.92$ & $4.01 \pm 1.57$ & .194 \\
\hline
\end{tabular}

Bold values indicate statistical significance.

and $1[0.6 \%], P<.001)$, low cardiac output syndrome (LCOS) (28 [12.4\%] and 10 [6.2\%], $P<.001)$ and postoperative atrial fibrillation $[35(15.6 \%)$ and $16(9.9 \%), P=.038]$ were significantly higher in poor CCC group. Postoperative 30-day mortality rate was significantly higher in poor CCC group (4 [1.7\%] and $1[0.6 \%], P<.001)$. Univariate and multivariate analyses were performed to determine the independent risk factors for LCOS development (Table 3). Older age (age $>65$ years) $(\mathrm{OR}=2.57,95 \%$ CI 1.34-3.57, $P<.001)$, incomplete revascularization $(\mathrm{OR}=2.14,95 \%$ CI $1.53-4.15$, $P=.024)$, LMCA lesion $(\mathrm{OR}=3.45,95 \%$ CI $1.65-5.42, P=$ $.045)$ are independent risk factors for LCOS after isolated CABG operation in high-risk patients. While there was no difference between preoperative and postoperative 6th hour CK-MB and cTn-I values, 12 th hour CK-MB (31.45 \pm 9.7 and $26.7 \pm 10.5, P=.044)$, cTn-I $(6.15 \pm 2.84$ and $5.58 \pm 2.19, P=$ $.021)$ and 24th hour CK-MB $(14.25 \pm 8.2$ and $9.22 \pm 5.7, P<$ $.001)$, cTn-I $(3.84 \pm 2.02$ and $2.1 \pm 1.91, P=.015)$ values were found to be significantly lower in the good CCC group (Table 4, Figure 1 and Figure 2).

\section{DISCUSSION}

This study showed that a well-developed coronary collateral system in high-risk patients has a positive effect on the preservation of myocardial viability during the CABG operation. Many previous studies showed that a well-developed CCC reduces mortality and morbidity in coronary artery diseases [Yaylak 2015; Seiler 2013]. This is the first study examining the effects of CCC on the preservation of myocardial viability in CABG operations according to our literature review.

Myocardial damage is not an unexpected condition in cardiac surgery. The magnitude of this myocardial injury affects the morbidity and mortality negatively in the medium to long-term [Paparella 2014]. The clinical situation in which the most destructive effects of myocardial damage were observed is postoperative myocardial infarction (PMI). In our study, no significant difference was found between the two groups in terms of PMI occurrence. Even though the collateral circulation contributes to the coronary circulation, its deficiency or weakness is not an independent variable for PMI occurrence, because PMI mainly develops due to early graft failure [Laflamme 2012]. If the postoperative myocardial injury is not associated with the early graft failure, it is usually clinically asymptomatic and silent [Flu 2010].

CK-MB and cTn-I enzymes are usually preferred to determine the extent of cardiac damage [Croal 2006]. In a metaanalysis in which Domanski et al included seven studies, they demonstrated that CK-MB or troponin elevations within the first 24 hours after CABG operation had an independent association with increased mortality in the medium and longterm [Domanski 2011]. In our present study, the values within the first 24 hours were evaluated; and when we compared the 12 th hour and 24th-hour values, the statistically significant difference observed between the two groups was the result which supported our hypothesis. Naturally, when comparing the results between the two groups with laboratory parameters, we also reached similar differences in clinical results. LCOS occurrence postoperatively is another important finding of the myocardial injury. There are different reasons for this pathology, which is quite challenging in the postoperative period such as advanced age, low LVEF, and incomplete revascularization [Ding 2015]. In our study, LCOS development in the good CCC group was significantly lower when compared to the poor CCC group. The high rates of incomplete revascularization in the poor CCC group also reinforce this situation. Although we could not obtain objective data to explain the higher rate of incomplete revascularization in this study, we believe that the vascular structure of the target coronary artery is better protected with a well-developed CCC, which encourages the surgeon to perform the anastomosis. When the 30-day mortality rates were assessed, patients in the good CCC group had significantly lower mortality rates.

A well-developed CCC is known to reduce the size of the affected ischemic area and associated complications in the ischemic heart diseases, especially in acute myocardial infarction [McMurtry 2011]. However, there are few studies related to $\mathrm{CCC}$ in $\mathrm{CABG}$ operations. In a study by Nathoe et al, they reported that $C C C$ reduced $P M I$ rates in off-pump $C A B G$ operations, but the same effect was not observed in on-pump CABG operations [Nathoe 2004]. On the other hand, they stated that in contrast to the idea we support in our hypothesis, the protective effect of collateral circulation may be reduced by the formation of cardiac arrest during on-pump surgery. In 
another report by Caputo et al, patients who underwent offpump CABG operations were examined in two groups as with or without collateral circulation. They reported that there was no difference in early-midterm clinical outcomes and this result was attributed to fewer risk factors in the non-collateral circulation group [Caputo 2008]. In contrast, in our study we think that evaluating Rentrop grade 1 patients and Rentrop grade 0 patients who do not have any collateral circulation in the same group provides a more homogeneous distribution. As a matter of fact, no difference was observed between the two groups in terms of preoperative risk factors.

It is not yet fully understood how the CCC circulation, angiogenesis, or more specifically, arteriogenesis, develops or what factors play a role in the formation of this adaptive system. Although tissue ischemia is widely believed to trigger the formation of collateral circulation, there is no clinical study that can prove this hypothesis. There are studies that report a correlation between hypertension, the severity of coronary stenosis, the location of the lesion, and how long the lesion is present with the development of CCC [De Marchi 2011; Piek 1997; Werner 2001]. Similarly, in our study, the incidence of hypertension and mean syntax score was higher in the good CCC group.

Although the importance of collateral circulation has been repeatedly emphasized by this and similar other studies, the question to be asked is whether this phenomenon is being used effectively as a therapeutical way or not. While the coronary collaterals are believed to have been present since the embryonic life, they are considered to be non-functional structures until they appear in the situations in which the circulation is degenerated, such as $\mathrm{CAD}$; a functional coronary collateral structure without CAD was demonstrated angiographically in a study of patients with normal coronary arteries [Wustmann 2003]. Yinglu Guan et al also reported in their study on animals that the natural processes of the cell cycle, such as proliferation, apoptosis, etc, are constantly active in this collateral vascular tissue [Guan 2016]. Activation of collateral circulation in a potentially short period of time may provide additional benefits in the management of stable CAD and $C A B G$ operations in the future.

\section{REFERENCES}

Adabag AS, Rector T, Mithani S, et al. 2007. Prognostic significance of elevated cardiac troponin I after heart surgery. Ann Thorac Surg 83:1744-50

Aldous SJ. 2013. Cardiac biomarkers in acute myocardial infarction. Int J Cardiol 164:282-94.

Caputo M, Anis RR, Rogers CA, et al. 2008. Coronary collateral circulation: effect on early and midterm outcomes after off-pump coronary artery bypass surgery. Ann Thorac Surg 85:71-9.

Croal BL, Hillis GS, Gibson PH, et al. 2006. Relationship between postoperative cardiac troponin I levels and outcome of cardiac surgery.
Circulation 114:1468-75.

De Marchi SF, Gloekler S, Meier P, et al. 2011. Determinants of preformed collateral vessels in the human heart without coronary artery disease. Cardiology 118:198-206.

Ding W, Ji Q, Shi Y, Ma R. 2015. Predictors of low cardiac output syndrome after isolated coronary artery bypass grafting. Int Heart J 56:144-9.

Domanski MJ, Mahaffey K, Hasselblad V, et al. 2011. Association of myocardial enzyme elevation and survival following coronary artery bypass graft surgery. JAMA 305:585-91.

Guan Y, Cai B, Liu Z, et al. 2016. The formation of aberrant collateral vessels during coronary arteriogenesis in dog heart. Cells Tissues Organs 201:118-29.

Laflamme M, DeMey N, Bouchard D, et al. 2012. Management of early postoperative coronary artery bypass graft failure. Interact Cardiovasc Thorac Surg 14:452-6.

McMurtry MS, Lewin AM, Knudtson ML, et al. 2011. The clinical profile and outcomes associated with coronary collaterals in patients with coronary artery disease. Can J Cardiol 27:581-8.

Meier P, Gloekler S, Zbinden R, et al. 2007. Beneficial effect of recruitable collaterals: A 10-year follow-up study in patients with stable coronary artery disease undergoing quantitative collateral measurements. Circulation 116:975-83.

Nathoe HM, Buskens E, Jansen EWL, et al. 2004. Role of coronary collaterals in off-pump and on-pump coronary bypass surgery. Circulation 110:1738-42.

Paparella D, Guida P, Caparrotti S, et al. 2014. Myocardial damage influences short- and mid-term survival after valve surgery: A prospective multicenter study. J Thorac Cardiovasc Surg 148:2373-9.e1.

Piek JJ, Van Liebergen RAM, Koch KT, Peters RJG, David GK. 1997. Clinical, angiographic and hemodynamic predictors of recruitable collateral flow assessed during balloon angioplasty coronary occlusion. J Am Coll Cardiol 29:275-82.

Rentrop KP, Thornton JC, Feit F, Van Buskirk M. 1988. Determinants and protective potential of coronary arterial collaterals as assessed by an angioplasty model. Am J Cardiol 61:677-84.

Seiler C. 2013. Assessment and impact of the human coronary collateral circulation on myocardial ischemia and outcome. Circ Cardiovasc Interv 6:719-28.

Sianos G, Morel M-A, Kappetein AP, et al. 2005. The SYNTAX Score: an angiographic tool grading the complexity of coronary artery disease. Euro Intervention 1:219-27.

Werner GS, Ferrari M, Betge S, Gastmann O, Richartz BM, Figulla HR. 2001. Collateral function in chronic total coronary occlusions is related to regional myocardial function and duration of occlusion. Circulation 104:2784-90.

Wustmann K, Zbinden S, Windecker S, Meier B, Seiler C. 2003. Is there functional collateral flow during vascular occlusion in angiographically normal coronary arteries? Circulation 107:2213-20.

Yaylak B, Altintas B, Ede H, et al. 2015. Impact of coronary collateral circulation on in-hospital death in patients with inferior st elevation myocardial infarction. Cardiol Res Pract 2015. 